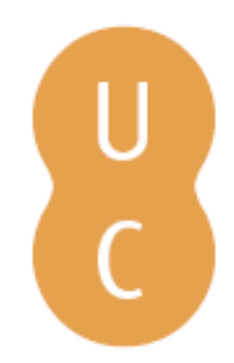

\title{
pommalina
}

\section{Turismo, lazer e património natural no destino Madeira}

Autor(es): $\quad$ Moreira, Claudete Oliveira; Figueiredo, Albano

Publicado por: Imprensa da Universidade de Coimbra

URL

persistente: URI:http://hdl.handle.net/10316.2/43528

DOI:

DOI:978-989-26-1348-2; DOI:https://doi.org/10.14195/978-989-26-13437_32

Accessed : $\quad$ 26-Apr-2023 00:12:42

A navegação consulta e descarregamento dos títulos inseridos nas Bibliotecas Digitais UC Digitalis, UC Pombalina e UC Impactum, pressupõem a aceitação plena e sem reservas dos Termos e Condições de Uso destas Bibliotecas Digitais, disponíveis em https://digitalis.uc.pt/pt-pt/termos.

Conforme exposto nos referidos Termos e Condições de Uso, o descarregamento de títulos de acesso restrito requer uma licença válida de autorização devendo o utilizador aceder ao(s) documento(s) a partir de um endereço de IP da instituição detentora da supramencionada licença.

Ao utilizador é apenas permitido o descarregamento para uso pessoal, pelo que o emprego do(s) título(s) descarregado(s) para outro fim, designadamente comercial, carece de autorização do respetivo autor ou editor da obra.

Na medida em que todas as obras da UC Digitalis se encontram protegidas pelo Código do Direito de Autor e Direitos Conexos e demais legislação aplicável, toda a cópia, parcial ou total, deste documento, nos casos em que é legalmente admitida, deverá conter ou fazer-se acompanhar por este aviso.

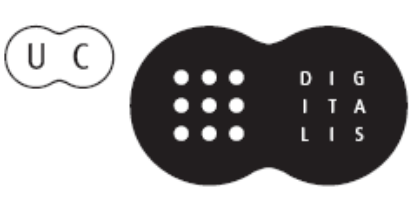




\section{FERNANDA CRAVIDÃO}

\section{IÚCIO CUNHA}

PAULA SANTANA

\section{NORBERTOSANTOS}

(ORG.)

\section{ESPAÇOS E TEMPOS EM GEOGRAFIA}

HOMENAGEM A ANTÓNIO GAMA

IMPRENISA DÁ UNIVERSIDADE DE COIMBRA COIMBRA UNIVERSITY PRESS

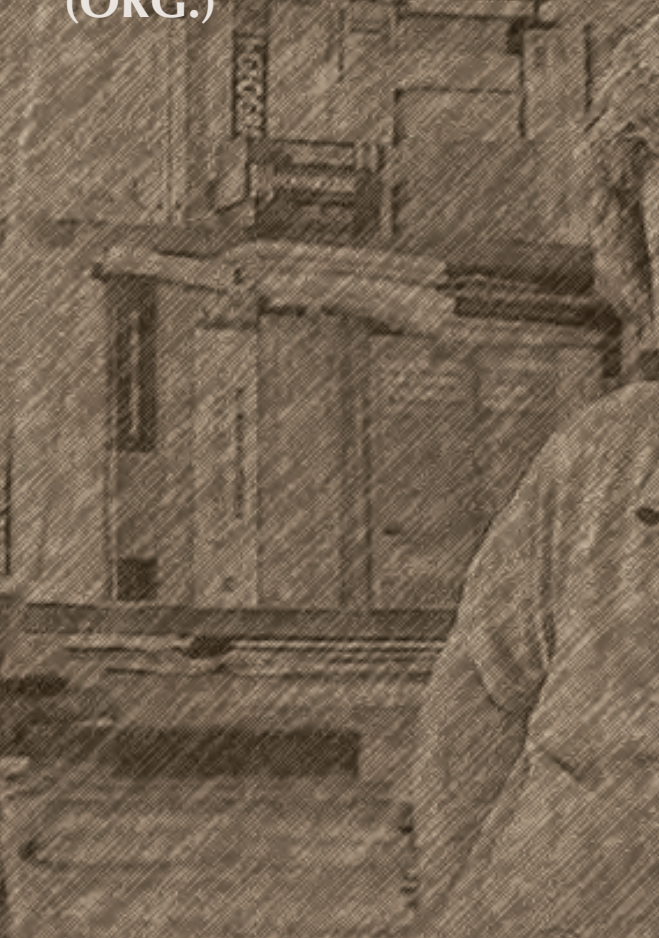




\title{
TURISMO, LAZER E PATRIMÓNIO NATURAL NO DESTINO MADEIRA
}

\author{
Claudete Oliveira Moreira/claudete@fl.uc.pt \\ Orcid.org/0000-0002-9188-191X \\ Departamento de Geografia e Turismo \\ da Universidade de Coimbra \\ e Centro de Estudos de Geografia \\ e Ordenamento do Território, CEGOT
}

\section{Albano Figueiredo/geofig@fl.uc.pt}

Orcid.org/0000-0003-0142-4764 Departamento de Geografia e Turismo da Universidade de Coimbra e Centro de Estudos de Geografia e Ordenamento do Território, CEGOT

\section{Nota prévia}

A primeira publicação científica efetuada pelo Dr. António Gama remonta a 1977, ano em que são editadas Algumas notas sobre as relaçóes entre a Geografia $e$ as Ciências Sociais. Em 1988 outras das suas vastas anotaçóes são dadas à estampa nas Notas para uma Geografia do tempo livre.

$\mathrm{O}$ modo como o ilustre intelectual e o magnânimo mestre intitula estas suas publicações, notas, ilustra bem uma preocupação: a de precisar aceçóes e relações. É digno de menção o modo despretensioso que elegia para partilhar o acervo científico de que era detentor: notas. Eram notas nas quais labutava, notas que alinhava, que no tempo guardava e que por vezes publicava. Os seus 
escritos, estas e outras das suas notas, constituem-se como subsídios científicos atemporais. Não menos digna de referência era a sua eloquência dilatada, sempre ancorada na Geografia mas de limites epistémicos imprecisos, o que a tornava particularmente sedutora. Todos os que lhe foram coevos conheceram um homem sage que se referenciava entre a comunidade de geógrafos. A sua disponibilidade, o seu enorme sentido de generosidade e a sua afabilidade permanecem como traços indeléveis do seu carácter.

Por entre os seus referenciais de memória que são as notas, o Dr. António Gama dedicou especial atenção, entre outros temas, à sociedade, ao espaço e ao tempo: à organizaçáo social e aos seus reflexos na organização do espaço geográfico, aos espaços de produção, de reprodução e de consumo, ao uso do tempo, ao tempo não livre e ao tempo livre, ao lazer e ao turismo. Nas palavras do próprio "as férias e o fim-de-semana deram origem, nas sociedades modernas, a um fenómeno de deslocação espacial ligado ao ócio, que assumiu uma grande magnitude nos nossos dias: o turismo” (Gama, 1988: 214; 2008 : 25). O turismo é, nas suas palavras, um "fenómeno por excelência ligado aos ócios modernos, evidencia, a partir do seu nascimento no início do século XIX, o aspeto dinâmico destes ócios" (Gama, 1988: 209; 2008: 22). E acrescenta que "o turismo é hoje um dos fenómenos de massa de maior importância económica, social e cultural" (Gama, 1988: 214; 2008: 25)1․

O presente tributo, in memoriam, ao Dr. António Gama, centra-se no turismo, elegendo como espaço geográfico de referência aquele que é um dos mais importantes destinos turísticos de Portugal: a Madeira ${ }^{2}$. Começa por se caracterizar, com base em alguns indicadores, o turismo no destino Madeira e por se evidenciar a sua expressão no território. Por se tratar de um destino

\footnotetext{
${ }^{1}$ Refira-se que entre 1991-1995 o Dr. António Gama foi investigador responsável pelo projeto de investigação: Turismo e cultura em Portugal: quatro estudos sobre mentalidades, práticas e impactos sociais, no Centro de Estudos Sociais.

${ }^{2} \mathrm{O}$ arquipélago da Madeira, de origem vulcânica, é constituído por duas ilhas habitadas (Madeira e Porto Santo) e por dois pequenos arquipélagos (Desertas e Selvagens) exclusivamente destinados à conservação da natureza. A ilha da Madeira é a maior das ilhas, com uma superfície de cerca de $758 \mathrm{~km}^{2}$. A ilha de Porto Santo, localizada a nordeste da ilha da Madeira, tem uma superfície de cerca de $43 \mathrm{~km}^{2}$, e possui seis ilhéus adjacentes.
} 
turístico insular valorizam-se as estruturas aeroportuárias e portuárias e a sua importância para o turismo. Pela relevância que o turismo de cruzeiros assume no destino, este é objeto de uma abordagem mais detalhada. No que à procura turística diz respeito analisa-se a sua evolução e a sua variação intra-anual, procurando estabelecer-se uma relação com a variação intra-anual das características climáticas bem como o calendário anual de eventos.

\section{O turismo no destino Madeira}

Os destinos turísticos insulares, territórios ultraperiféricos espartilhados pelo mar, têm no turismo uma importante atividade socioeconómica, e no património natural, no clima, nas paisagens e na biodiversidade importantes vantagens comparativas. $\mathrm{O}$ arquipélago da Madeira não constitui exceção.

A Madeira individualiza-se no contexto nacional por ser a mais antiga estância turística de Portugal. Trata-se de um destino turístico com uma matriz acentuadamente cosmopolita, relativamente consolidado e competitivo (Moreira, 2013: 212-214), que possui um património histórico construído, natural e imaterial relativamente bem conservado e uma oferta hoteleira bastante qualificada, onde os hotéis de 4 e de 5 estrelas representam $78 \%$ da oferta de alojamento. O rendimento por quarto disponível (RevPAR) da Madeira era, em 2015, de 37,9 euros, um dos mais elevados do destino Portugal, que se ficava pelos 35,0 euros $^{3}$. Ainda assim modesto face a outros destinos com os quais compete mais diretamente, como as ilhas Canárias, em que o RevPAR, no mesmo ano, foi de 54,2 euros ${ }^{4}$. Para a qualificação da oferta muito relevam os agentes de animação turística. O número de agentes registados no Turismo de Portugal, neste destino, era em agosto de 2016 de 80, o que significava 2,8\% dos agentes registados no país, computando-se 24 operadores marítimo-turísticos, 2,6\% do

\footnotetext{
3 INE (2016). Apuramento especifico do RevPAR 2015, por municipio. Lisboa: Instituto Nacional de Estatística.

${ }^{4}$ ISTAC (2016). RevPAR 2015. Gran Canária: Instituto Canario de Estadística.
} 
destino Portugal. Estes agentes concentram-se, principalmente, nos municípios do Funchal e de Santa Cruz (Figura 1).

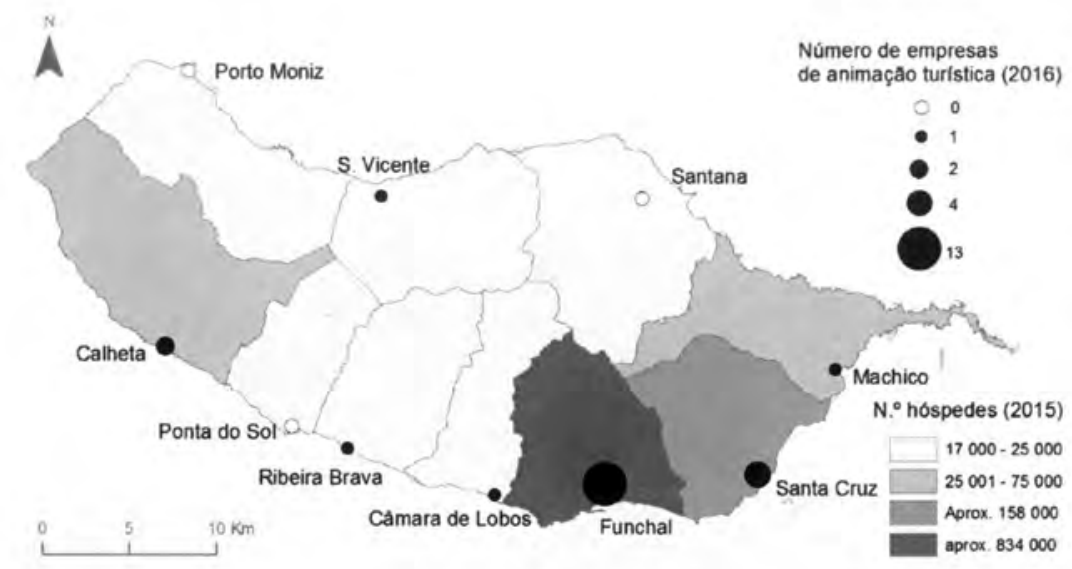

Figura 1

Total de hóspedes (2014) e número de empresas de animação turística registadas (2016), por concelho na ilha da Madeira

Fontes de dados: Anuário Estatístico da Região Autónoma da Madeira 2015, Instituto Nacional de Estatística, Lisboa; Registo Nacional de Agentes de Animação Turística 2016, Turismo de Portugal, Lisboa.

No destino Madeira, enquanto os circuitos turísticos, nomeadamente os associados ao turismo de natureza, se apresentam como produtos consolidados, outras ofertas estáo ainda em fase de desenvolvimento, como é o caso do turismo náutico. Os resorts integrados e o turismo residencial afirmam-se como produto turístico emergente. Outros produtos surgem como complementares, como é o caso do turismo de saúde e bem-estar. Refira-se que as naturoterapias (a climatoterapia, a helioterapia, a hidroterapia, a talassoterapia, a psamoterapia, a arenoterapia, a crenoterapia, a oligoterapia, a peloterapia), enquadradas hoje no turismo de saúde e bem-estar, sempre encontraram no arquipélago da Madeira condiçóes muito favoráveis, motivando a procura turística. A ilha do Porto Santo constitui-se mesmo como uma estância singular de saúde natural, como demonstram Gomes e Silva (2012). Esta ilha possui, na sua face sul, 
uma praia com um areal extenso, com cerca de $9 \mathrm{~km}$, sendo reconhecidas as propriedades terapêuticas e medicinais da sua areia dourada de gráo fino. As propriedades físicas, térmicas e químicas das areias do Porto Santo permitem o tratamento de doenças do foro reumático, fisiátrico e ortopédico, constituindo-se os "banhos de areia" do Porto Santo como uma referência terapêutica. Às propriedades terapêuticas das areias do Porto Santo somam-se as propriedades das suas argilas esmectíticas e das águas marinhas, cuja temperatura ronda os $22^{\circ} \mathrm{C}$ no estio e os $17^{\circ} \mathrm{C}$ no inverno, apresentando apreciáveis concentraçóes de iodo (I), cálcio $(\mathrm{Ca})$, magnésio $(\mathrm{Mg})$ e estrôncio $(\mathrm{Sr})$, um anti-inflamatório natural. Estes particularismos levaram à criação na ilha, em 2000, de um Centro de Talassoterapia, e em 2008 de um Centro de Geomedicina, ambos integrados em empreendimentos turísticos. A par da saúde e bem-estar, também o golfe e a gastronomia e vinhos são produtos turísticos complementares, contribuindo, decisivamente, para diversificar e valorizar as experiências turísticas. Refira-se que no destino Madeira, em 2014, existiam 1141 estabelecimentos de restauração e similares, sendo que $516(45 \%)$ eram restaurantes tradicionais e 33 (3\%) eram restaurantes típicos ${ }^{5}$, relevantes para promover as tradições gastronómicas locais e para tornar as experiências diferenciadas e autênticas. A atribuição de vários prémios, como o Europe's Leading Island Destination (2013 e 2014) e o The World's Leading Island Destination (2015 e 2016) comprova a existência de condiçôes únicas e diferenciadoras, atestando a excelência da oferta turística no destino Madeira. Em termos de procura turística, o destino apresenta a maior internacionalizaçáo do destino Portugal (81,4\% de hóspedes estrangeiros), assim como a maior estada média em estabelecimentos de alojamento turístico $(5,4 \text { noites })^{6}$.

A ilha da Madeira, sendo a de maior dimensão do arquipélago e a que concentra a maior parte da população residente (98\%), é também o principal

5 ACIF-CCIM (2015). Documento estratégico para o turismo na RAM. Relatório diagnóstico ao atual posicionamento da Madeira. Funchal: Associação Comercial e Industrial do Funchal, Câmara de Comércio e Indústria da Madeira.

${ }^{6}$ INE (2016). Anuário Estatístico da Região Autónoma da Madeira, 2015. Lisboa: Instituto Nacional de Estatística. 
destino dos turistas. No Funchal e em Santa Cruz concentram-se 68,2\% dos estabelecimentos hoteleiros, 76,6\% dos hóspedes (Figura 1) e 80,6\% das dormidas ${ }^{16}$. Vários municípios da ilha estão entre os municípios que em Portugal apresentam um RevPAR mais elevado, sendo merecedores de referência a Ponta do Sol, com 39,4 euros, o Funchal com 44,0 euros e a Santa Cruz com 33,6 euros ${ }^{5}$. O que comprova não só a sua importância turística como a qualidade dos empreendimentos turísticos que, ainda assim, carecem, em certos casos, de intervenções de reabilitação e de modernização para que se qualifique a oferta.

O crescimento, no tempo, da atividade turística é inexorável, com reflexos no território, porque, como o próprio Dr. António Gama refere, “o turismo se tornou um consumidor de espaço" (Gama, 1988: 212; 2008: 23). Contudo, o turismo faz "um uso diferenciado do espaço", sendo responsável por "uma penetração e transformação dos espaços de reserva, a praia, a montanha e o campo" (Gama, 1988: 212; 2008: 24). A ilha da Madeira não constitui exceção, sendo evidente a importância que o incremento do turismo teve na definição de funcionalidades associadas em áreas significativas da cidade do Funchal, nomeadamente na área costeira no setor ocidental da cidade, sobretudo no Lido, litoral sul da freguesia de São Martinho, onde se localiza um importante número de empreendimentos turísticos de grande volumetria (Figura 2 - esquerda). Onde, de acordo com Brito-Henriques (2008: 130) "se desenvolveu uma extensão urbana de clara vocação turística, de tipo "riviera". Esta dedicação do espaço a empreendimentos turísticos ocorre mesmo nos setores mais altos da cidade, afastados do litoral, ainda que essa função resulte de um processo de reconversão das quintas de aluguer oitocentistas, que surgem a meia encosta, propriedades da aristocracia local ou de mercadores britânicos que beneficiaram do mercadejar do vinho da Madeira nos séculos XVII e XVIII. Não raras vezes com laivos da arquitetura inglesa de expressão romântica, têm no jardim um elemento essencial, o qual assume frequentemente dimensóes importantes. Alguns destes espaços são convertidos em empreendimentos turísticos, e noutros os seus jardins funcionam na atualidade como atração turística (Figura 2 - direita). 

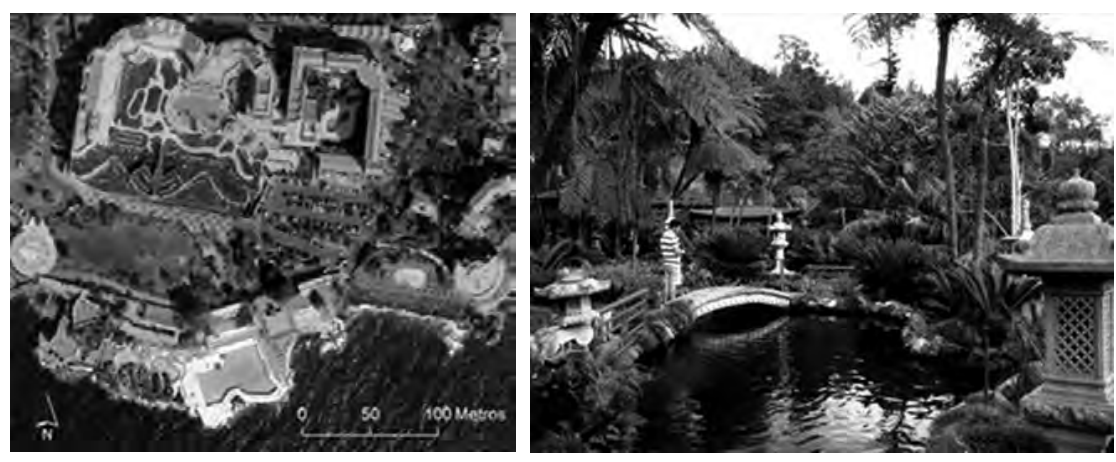

Figura 2

Vista aérea sobre empreendimento turístico no setor ocidental do Funchal (esq.), e Jardim Tropical Monte Palace, freguesia do Monte - Funchal (dir)

Fonte da imagem aérea: Secretaria Regional do Equipamento Social da Região Autónoma da Madeira, 2011. Fotografia de Albano Figueiredo, 2016.

Mesmo fora do Funchal, centro que polariza a atividade turística não só em termos de empreendimentos turísticos, de oferta de atividades de animação turística, como também no número de hóspedes, não raras vezes a paisagem sofre alterações significativas decorrentes da instalação de empreendimentos turísticos, os quais se destacam na paisagem pela volumetria. Os empreendimentos voltados para o turismo rural, esses encontram-se localizados na costa da face norte da ilha, afastados do epicentro da atividade turística, como refere Almeida (2010: 103).

Nos territórios insulares a construção de estruturas aeroportuárias e o estabelecimento de ligaçóes aéreas regulares são fundamentais para viabilizar a economia em geral, e a atividade turística em particular. No arquipélago da Madeira os aeroportos foram extremamente importantes, pois permitiram um aumento significativo do número de turistas. As primeiras ligaçôes aéreas regulares iniciaram-se em 1949, sendo então asseguradas por hidroavióes que amaravam na baía do Funchal, uma enseada que se estende entre a Ponta da Cruz e a Ponta do Garajau, e que é abrigada dos ventos dominantes do quadrante norte e dos ventos de oeste. É na década de sessenta do século xx que o 
arquipélago da Madeira passa a beneficiar dos seus dois aeroportos, estruturas que sempre se complementaram: o aeroporto do Porto Santo, inaugurado em 1960, e o Aeroporto da Madeira, inaugurado em 1964. As intervençôes de que, desde então, ambos têm beneficiado muito relevam para o crescimento do número de turistas no arquipélago, contribuindo para a internacionalização do destino turístico. Sendo a ilha da Madeira o destino turístico principal, são importantes as diferenças existentes em termos de número de passageiros internacionais desembarcados nos dois aeroportos, sendo o valor do aeroporto da Madeira substancialmente superior (Figura 3).

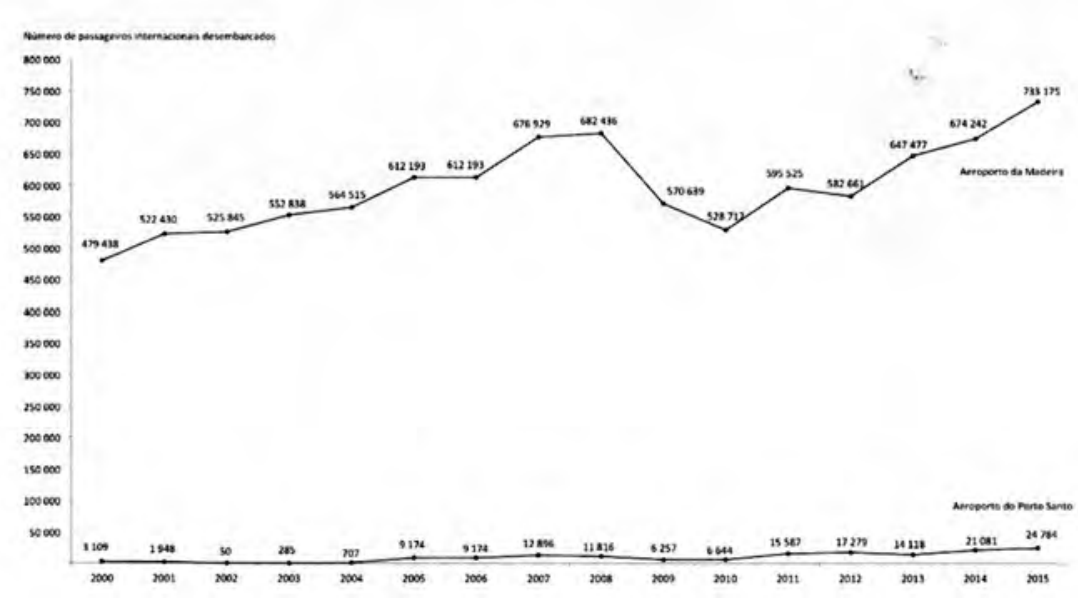

Figura 3

Número de passageiros internacionais desembarcados nos aeroportos da Madeira e do Porto Santo (2000-2015)

Fonte dos dados: Anuários Estatísticos da Região Autónoma da Madeira de 2000 a 2015, Instituto Nacional de Estatística, Lisboa.

Mas nos territórios insulares não relevam só as estruturas aeroportuárias, as estruturas marítimas são igualmente importantes. 


\section{A relevância do turismo de cruzeiros no destino Madeira}

Pela sua posição, no centro Atlântico, a ilha da Madeira constitui-se como um porto de escala transoceânico entre a Europa e a América, sendo igualmente relevante nas linhas de tráfego da fachada atlântica da Europa e do Mediterrâneo ocidental, bem como para os cruzeiros entre as ilhas atlânticas da Macaronésia (Canárias, Cabo Verde e Açores) e para os cruzeiros da costa norte de África (Agadir, Casablanca, Tânger, entre outros). Tendo em conta este enquadramento, o Porto do Funchal constituiu-se, secularmente, como um porto de escala e de abastecimento.

O facto de no segundo quartel do século xx o Porto do Funchal evidenciar constrangimentos vários, como por exemplo náo dispor de depósitos de combustíveis líquidos que permitissem o abastecimento dos navios, comprometia a atracação de embarcações. A concorrência dos portos das ilhas Canárias, de Santa Cruz de Tenerife e de Las Palmas, em termos de condiçôes das estruturas, de serviços oferecidos, de acostagem e de abastecimento de combustíveis, de eficiência, de segurança, de comodidade e de custos, acentuava-se, levando a um decréscimo da importância turística, mas também comercial, do Porto do Funchal, não só durante a II Guerra Mundial, em que entrou numa crise profunda (Ribeiro, 1985: 128-129), o que era até certo ponto compreensível, como também após este conflito, o que era preocupante. Esta situação altera-se em 1961, com a conclusão das obras do molhe da Pontinha. Neste período o Porto do Funchal continuava a desempenhar um papel fundamental como principal plataforma de acesso à ilha. Era importante não só para os navios de cruzeiro, como os navios soviéticos que operavam nas décadas de 60/70 do século xx a partir de São Petersburgo com passageiros oriundos dos países nórdicos, como para as ligaçóes regulares entre Portugal Continental e as ex-colónias, servindo ainda de escala aos emigrantes portugueses que rumavam ao Brasil e à Venezuela.

As décadas de 80 e de 90 do século xx corresponderam a um decréscimo dos tráfegos que escalavam no Porto do Funchal, justificável pela perda de importância do transporte marítimo de passageiros de média e de longa distância, e pelo desenvolvimento do transporte aéreo, uma situação que se começa a inverter a 
partir de finais da década de 90 do século $\mathrm{xx}$, mais concretamente a partir de 1997 (veja-se Sousa, 2004: 349), altura em que começa a recrudescer a importância do turismo de cruzeiros. Tendo em conta a importante procura por este tipo de turismo, o Porto do Funchal passa a estar vocacionado exclusivamente para navios de passageiros a partir de $2004^{7}$, deslocando as mercadorias para o Porto do Caniçal. No sentido de oferecer melhores condições de desembarque, principalmente aos turistas de cruzeiros, realizam-se obras de melhoramento, levando à construção, no cais sul, no cais da Pontinha, da Gare Marítima Internacional de Cruzeiros, inaugurada em 2010. A partir de 2015, e na sequência de obras na frente mar da cidade do Funchal, passa a funcionar um novo cais de acostagem de navios cruzeiro, o cais 8 , permitindo ampliar a capacidade do porto para receber 6 navios de cruzeiro em simultâneo.

A acostagem de navios de cruzeiro faz-se também no Porto da ilha do Porto Santo, tendo, ainda assim, de ser compatibilizada com a acostagem do navio Lobo Marinho que faz a ligaçáo com o Porto do Funchal. O Porto do Porto Santo acolhe um escasso número de escalas de navios de cruzeiro, tendo em 2015 recebido apenas 4 navios de cruzeiro, o que representou 1856 passageiros, pelo que a captaçấo de escalas se torna estratégica em termos de gestáo do destino.

No sentido de captar mais escalas de navios de cruzeiro, a 19 de dezembro de 1994 as autoridades portuárias do arquipélago da Madeira, de Santa Cruz de Tenerife e de Las Palmas criaram uma associação, a Cruises in the Atlantic Islands, para promover internacionalmente a escala de navios de cruzeiro nos seus portos e reforçar a rota das ilhas atlânticas, uma rota ancorada em portos de ilhas que se encontram a poucas horas de navegação entre si, ilhas com características singulares e diferenciadas, o que permite estruturar uma oferta de atraçôes turísticas complementares. As autoridades portuárias de Cabo Verde associaram-se em 2015 à Cruises in the Atlantic Islands, o que traduz uma intenção clara de alargar e reforçar a marca rota das ilhas atlanticas, uma rota que certamente se valorizaria com a integraçáo do arquipélago dos Açores, ainda que com uma latitude mais setentrional.

${ }^{7}$ Ano em que foi aprovado o Plano Director do Porto do Funchal. 
O número de navios de cruzeiro que fazem escala no Porto do Funchal tem vindo a aumentar de um modo contínuo de 2000 a 2012, ano em que se registaram 592935 passageiros e 336 escalas de navios, tendo sido este o melhor ano de sempre do Porto do Funchal (Figura 4). Registou-se uma quebra pontual nos anos de 2013 e 2014, havendo uma retoma expressiva em 2015. No ano de 2015 registou-se uma média diária de 1585 passageiros de navios de cruzeiro no Porto do Funchal, o que contrasta com a média diária de 465 passageiros no ano 2000. Esta variação estará associada, entre outros fatores, aos investimentos que têm sido efetuados no Porto do Funchal, ao facto de a Administração dos Portos da Região Autónoma da Madeira ter desenvolvido parcerias com outras administraçóes portuárias, ao facto de integrar novas associaçôes internacionais, e ter havido investimento na promoçáo internacional do porto, ao marcar presença nos maiores eventos, designadamente feiras de cruzeiros. Outros aspetos, não negligenciáveis, são o facto de o turismo de cruzeiros evidenciar um crescimento muito apreciável, de aumentarem em número os navios de cruzeiro, de estes se especializarem, se tematizarem e segmentarem crescentemente, de possuírem maior capacidade de transporte de passageiros, de apresentarem taxas de ocupação mais elevadas, e de se diversificarem as origens e os destinos turísticos, bem como os circuitos.

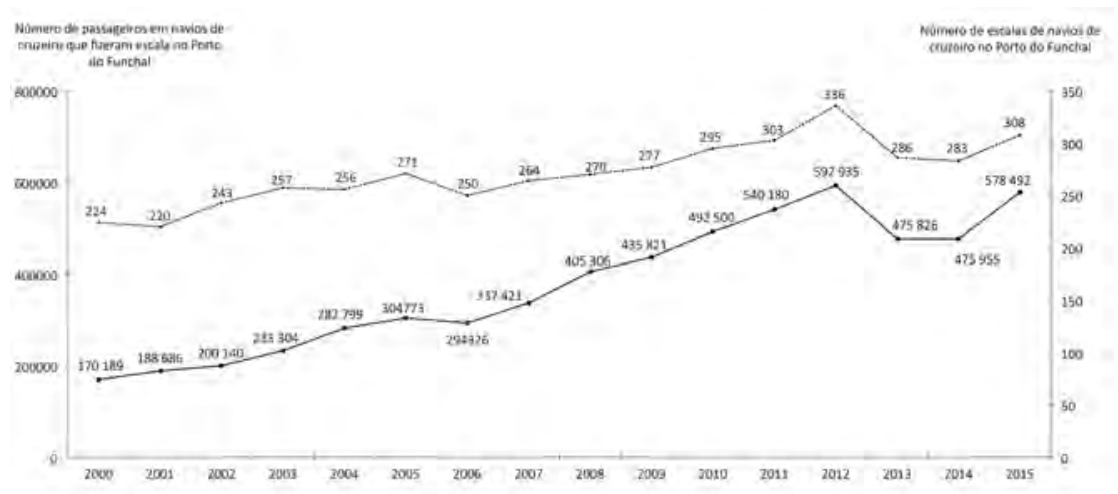

Figura 4

Número de passageiros em navios de cruzeiro que fizeram escala no Porto do Funchal e número de escalas (2000-2015)

Fonte dos dados: Administração dos Portos da Região Autónoma da Madeira, 2016. 
As iniciativas de promoçấo internacional dos portos do arquipélago da Madeira são essenciais, pois há uma acentuada sazonalidade da atividade dos navios de cruzeiro. No Porto do Funchal a distribuiçáo intra-anual das escalas e dos passageiros em navios de cruzeiro evidencia uma variação muito apreciável (Figura 5). Considerando o ano de 2015, há um aumento das escalas no Porto do Funchal na primavera e no inverno. Cerca de $85 \%$ das escalas concentram-se de outubro a abril (compensado a sazonalidade das dormidas que está expressa na Figura 11), sendo que a maior afluência de navios de cruzeiro se verifica nos meses de abril, novembro e dezembro (Figura 5). Efetivamente, o turismo de cruzeiros contribui para que o Funchal seja um dos mais movimentados destinos turísticos no período outono/inverno. Nos meses de novembro e dezembro é significativo o número de navios de cruzeiro que fazem escala no Porto do Funchal, e que efetuam o circuito das ilhas atlânticas. Um dos momentos com um número mais elevado de navios de cruzeiro está associado ao último dia do ano, em que estes navios atracam na baía do Funchal para assistir ao fogo de artifício do final do ano.

Na primavera as escalas aumentam nos meses de março, abril, época do ano em que adquirem expressão significativa os navios de cruzeiro que fazem a travessia do Atlântico, entre a Europa e a América, navios que reposicionam as suas operaçôes (que no veráo, de março a outubro, operam nos países nórdicos, designadamente nos fiordes e nos glaciares do norte da Europa, ou no Mediterrâneo, e que no inverno europeu se deslocam para as Caraíbas).

Ora é estratégico, em termos de gestão do destino, aumentar as escalas dos navios de cruzeiro nos meses de verão, tendo em conta a redução significativa do número de navios de cruzeiro que visitam o Funchal (Figura 5). Nesta estaçáo do ano o Porto do Funchal está integrado, principalmente, nos circuitos da costa norte de África e Mediterrâneo ocidental. O facto de haver nesta estaçâo a deslocação de um número significativo de navios para o mar Báltico e para o mar Mediterrâneo transforma este objetivo num desafio importante. 


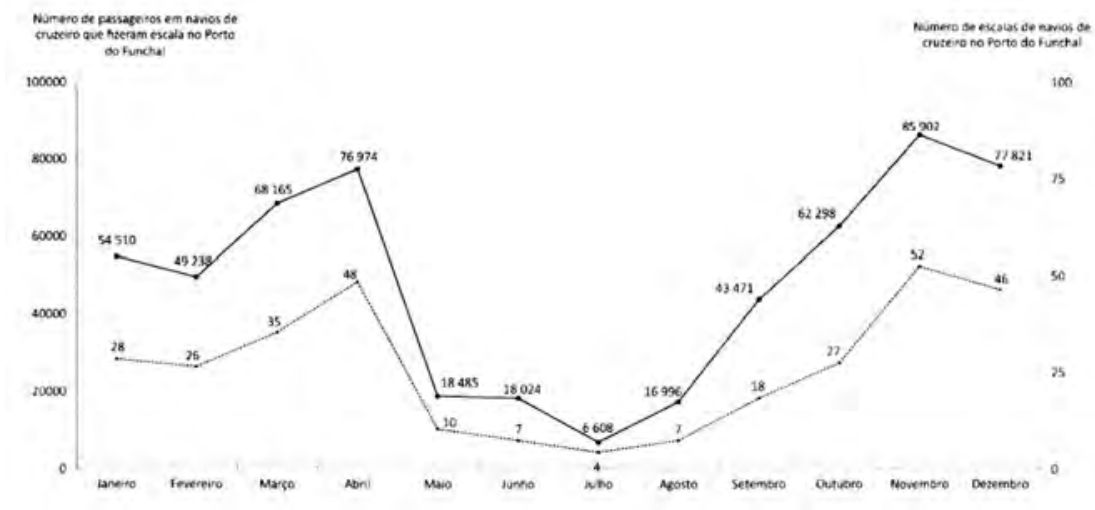

Figura 5

Número de passageiros em navios de cruzeiro com escala no Porto do Funchal e número de escalas (2015)

Fonte dos dados: Administração dos Portos da Região Autónoma da Madeira, 2016.

Considerando a singularidade e a notoriedade do destino Madeira, a qualidade dos empreendimentos turísticos existentes na ilha, a posição atlântica do Porto do Funchal, a sua já longa tradição na acostagem de navios de cruzeiro, a existência de um aeroporto intercontinental que permite viabilizar os fly cruises, a que se junta a Gare Marítima Internacional de Cruzeiros, é estratégico para o destino Madeira que as operaçóes de turnaround sejam crescentemente valorizadas, que o Porto do Funchal deixe de ser apenas um porto de trânsito, e se afirme, cada vez mais, como um home port. Tal pressupóe a permanência em terra de tripulaçóes e de passageiros, constituindo-se a prestação de serviços pre-cruise e post-cruise como extremamente importante e com impacto económico na ilha.

Em suma, as estruturas aeroportuárias e portuárias têm permitido a chegada ao arquipélago da Madeira de um número crescente de turistas e uma expansão da atividade turística. A justificar a procura turística anteriormente exposta estão fatores associados à paisagem, ao clima e aos eventos culturais, os quais, numa lógica de complementaridade, muito contribuem para a afirmação da Madeira 
como destino turístico (Oliveira e Pereira, 2008: 3; Quintal, 2010: 169-170; Marujo, 2012; Marujo, 2015: 7), como se terá oportunidade de demonstrar.

\section{Património natural, clima e eventos no destino Madeira}

Os atributos naturais assumem uma importância primordial na afirmação do destino Madeira, ajudando a consolidar a sua posição como destino turístico. Beneficiando da inata atratividade que as ilhas oceânicas apresentam como destinos turísticos, a Madeira apresenta um património natural de caráter excecional, o que justifica o seu destaque no âmbito das regióes turísticas portuguesas, muito contribuindo esta vantagem comparativa para a sua competitividade entre os destinos turísticos internacionais.

O património natural está identificado como a principal atração, dado que o contacto com a natureza é um importante fator motivacional para a visita (Quintal, 2010:170,188-189), tal como o confirmam os resultados do estudo realizado pela Secretaria Regional de Turismo e Transportes da Madeira em 2010, onde o "contacto com a natureza" e o "sol e mar" se assumem como as motivações principais para a procura turística (SRTTM, 2010: 6). E a imagem de marca Madeira, como destino turístico, tem explorado a exclusividade destes atributos naturais, valorizando o seu enquadramento insular, o seu clima ameno associado à sua posição subtropical, a presença de uma floresta classificada como Património Natural da UNESCO (floresta Laurissilva), ou a possibilidade de atravessar paisagens naturais de grande interesse, utilizando circuitos como levadas, veredas ou caminhos reais (antigas vias de comunicação). Na verdade, estes atributos têm assumido especial relevo no branding deste destino turístico, sendo comum o uso de imagens e palavras associados ao mar, ao sol, à montanha, à paisagem natural, à Laurissilva ou às levadas, elementos cuja combinação se torna especialmente atrativa para turistas procedentes de territórios europeus onde alguns destes elementos não estão presentes. Além de questóes de natureza económica, nomeadamente disponibilidade de orçamento para viajar, a existência de atributos naturais exclusivos pode ser um fator que explica a 
preponderância de países como o Reino Unido, a Alemanha e a França como os países mais representados em termos de origem dos turistas que procuraram a Madeira em 2015 (DREM, 2016).

\section{Diversidade de paisagens}

Apesar de ser uma ilha pequena $\left(758 \mathrm{~km}^{2}\right)$, a Madeira apresenta uma grande diversidade de ambientes, estruturada por diferenças climáticas importantes, elevada complexidade topográfica (Figura 6), associada a um profundo encaixe da rede hidrográfica, e paisagens bastante diferenciadas em função do tipo de vegetação e uso do solo.
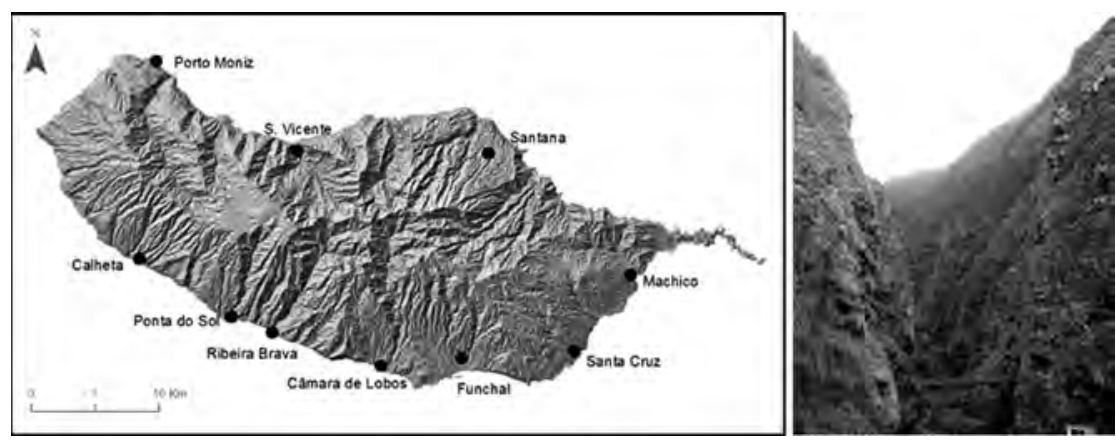

\section{Figura 6}

Aspeto geral do relevo da ilha da Madeira (esq.), e vale encaixado da ribeira do Inferno (dir.) Fotografia de Albano Figueiredo, 2016

A ilha da Madeira apresenta uma grande diversidade de ambientes naturais (Figura 7). Assim, em curtas distâncias percorridas, é possível passar do fundo de um vale ladeado por vertentes abruptas para um planalto (Paul da Serra); subir aos picos escarpados de maior altitude da ilha, ou descer a uma pequena praia de $c a l h a u^{8}$; fazer um percurso numa paisagem desprovida de floresta

\footnotetext{
${ }^{8}$ Designação local atribuída às praias de calhaus rolados caraterísticas da ilha da Madeira.
} 
(Ponta de S. Lourenço), ou penetrar na floresta Laurissilva; caminhar ao longo de uma levada, praticamente sempre à mesma cota altimétrica, ou cruzar a ilha através de veredas e caminhos reais, permitindo usufruir de paisagens naturais de elevado interesse.

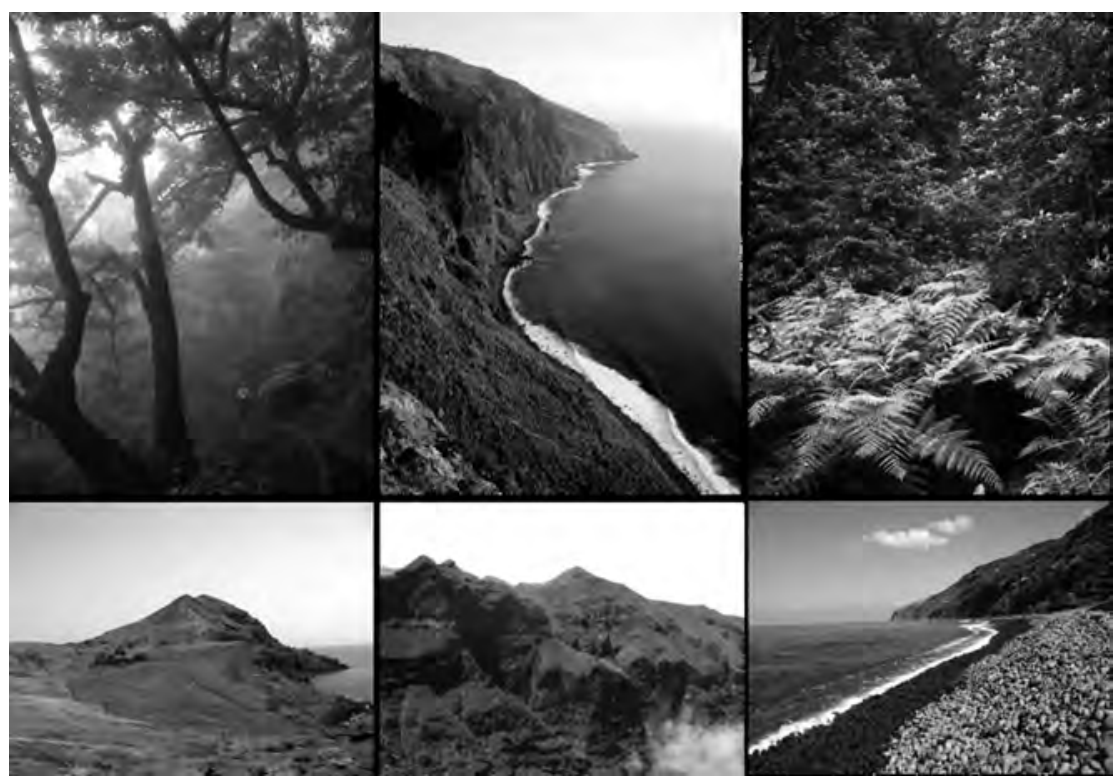

Figura 7

Diversidade de paisagens na ilha da Madeira Fotografias de Albano Figueiredo, 2016

Os setores de maior altitude apresentam-se normalmente desprovidos de floresta, predominando uma paisagem dominada por vegetação herbácea ou formaçóes arbustivas baixas, pois trata-se de áreas associadas ao pastoreio ao longo de séculos. Podendo ser áreas de passagem, funcionam ainda como pontos de paragem, especificamente alguns pontos dos setores mais elevados da ilha, onde normalmente estão instalados miradouros (Pico Ruivo, Pico Areeiro, Bica da Cana, Pico Ruivo do Paul) (Figura 8). Nestes pontos é possível contemplar áreas significativas da ilha, obtendo-se uma vista privilegiada sobre os picos escarpados, vales encaixados, ou manchas de floresta Laurissilva, um outro elemento natural de interesse para o turismo. 


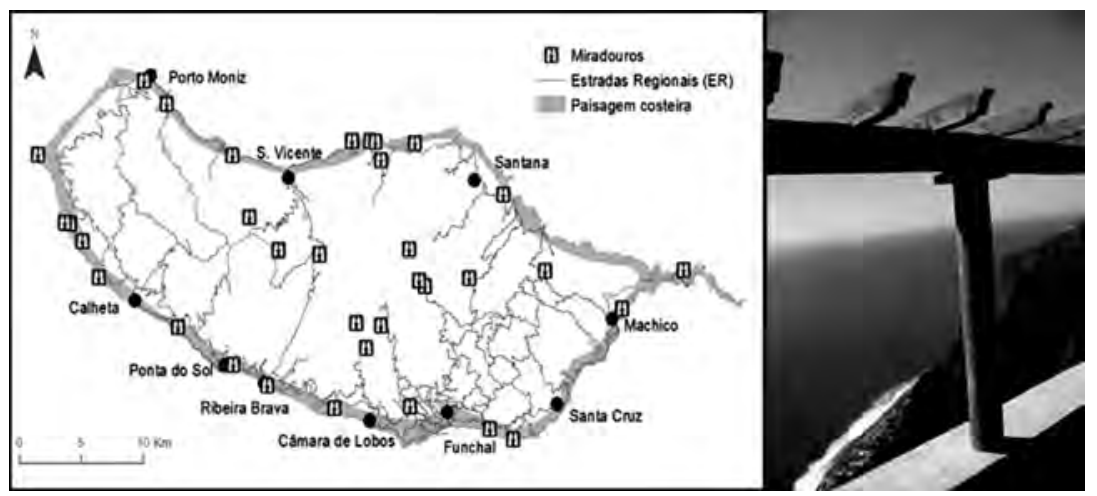

Figura 8

Localização de miradouros na ilha da Madeira (2016) (esq.) e pormenor do Miradouro do Lombo da Rocha, Calheta (dir.)

Fotografia de Albano Figueiredo, 2016

Vários fatores contribuem para transformar a floresta Laurissilva ${ }^{9}$ numa das principais atraçóes da ilha da Madeira. Trata-se de uma floresta de elevado valor do ponto de vista da conservação, um aspeto traduzido na classificação como Património Natural da Humanidade pela UNESCO, desde 1999. Além de integrar árvores exclusivas das ilhas da Macaronésia, esta floresta, que ocupa uma área de cerca de 15000 hectares, aproximadamente $20 \%$ da superfície da ilha, inclui ainda arbustos endémicos exclusivos da ilha da Madeira, alguns deles associados a pequenas clareiras definidas pela presença de cascatas e ribeiras no seu interior (Figura 9). Tendo em conta os elevados totais pluviométricos e a elevada frequência de nevoeiros nas áreas onde a floresta Laurissilva ainda persiste, quase exclusivamente na face norte da ilha, esta é rica em epífitos (plantas, líquenes e musgos que cobrem os troncos e ramos das árvores) e pteridófitos (fetos), que lhe conferem um aspeto semelhante a algumas florestas tropicais.

$\mathrm{O}$ acesso à floresta Laurissilva faz-se normalmente através de levadas (Figura 10), pequenos canais associados ao sistema de irrigação que foi instalado na ilha para permitir suprir as necessidades de água na face sul, que sendo a área mais seca da ilha é também a que concentra a maior parte da população,

\footnotetext{
${ }^{9}$ Floresta dominada por árvores da família das lauráceas, como o loureiro (Laurus novocanariensis), o til (Ocotea foetens), o vinhático (Persea indica) e o barbusano (Apollonias barbujana).
} 
área agrícola e infraestruturas hoteleiras. Orlando Ribeiro (1985: 64) refere-se às levadas afirmando: "estes aquedutos são aparentemente muito simples: um canal, construído em alvenaria, com a profundidade de meio metro e a largura de 70 centímetros, geralmente acompanhado de uma estreita plataforma onde se dispôs um caminho". Os caminhos que correm paralelos às levadas constituem-se como trilhos, sendo valorizados pelas empresas de animação turística, pois permitem um contacto mais próximo e intimista com a natureza, valorizando a experiência turística. Alguns dos trilhos que acompanham as levadas permitem aceder a vales encaixados onde se encontram algumas das manchas melhor preservadas de Laurissilva das ilhas da Macaronésia, onde é possível contactar com alguns dos atributos mais exclusivos da floresta (Figura 9).

Estes percursos têm uma forte relação com o elemento água, pois estas levadas cruzam regularmente pequenas ribeiras, algumas delas dando origem a cascatas quando instaladas em ruturas de declive, ou pela frequência de paredes ressumantes que debitam continuamente água nestes canais.

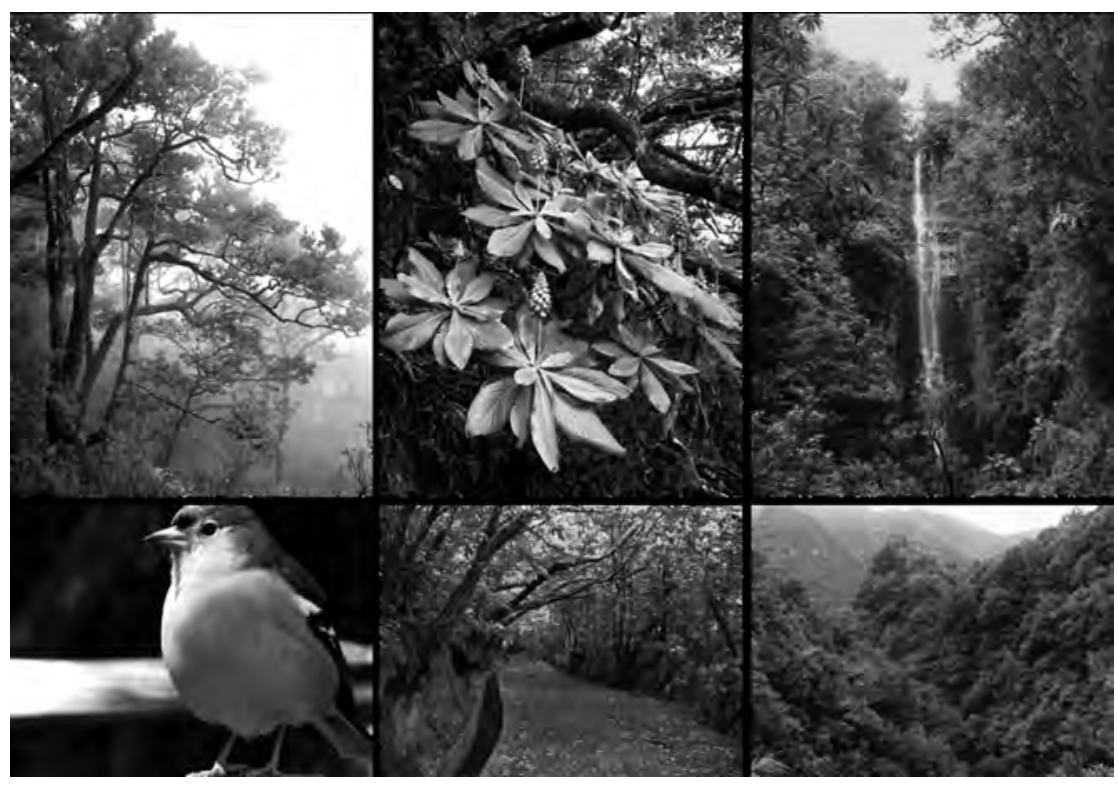

Figura 9

Aspetos da floresta Laurissilva e espécies endémicas da flora e da fauna Fotografias de Albano Figueiredo, 2016 
O início da construção das levadas remonta ao início da ocupação da ilha, na centúria de quinhentos, mas foi o aumento da área agrícola que motivou a necessidade de caudais cada vez mais elevados, determinando a criação de uma rede mais densa e extensa, a qual permitiu garantir disponibilidade de água aos diferentes ciclos agrícolas da ilha, desde a cana-de-açúcar nos séculos XVI e XVII, ao ciclo do vinho nos séculos XVIII e XIX, e o da banana no século Xx.

Com uma extensão total próxima dos $3000 \mathrm{~km}$ (Figura 10), as levadas constituem-se como um particularismo deste território insular, muito contribuindo para a singularidade e notoriedade do destino Madeira. Assim se compreende o facto de as levadas da Madeira integrarem presentemente a lista indicativa do Estado português a Património Mundial da UNESCO.

A combinação destes dois elementos, da floresta Laurissilva e das levadas, faz com estes percursos sejam dos mais procurados pelos turistas que realizam percursos pedestres, pela possibilidade de poder atravessar uma floresta com atributos exclusivos e aceder a locais da ilha com paisagens únicas, ainda que nem todas as levadas estejam ativas, e nem todas cumpram as normas de segurança necessárias à utilização para práticas de lazer e de turismo. Sublinhe-se que alguns dos trilhos das levadas, mesmo não sendo percursos sinalizados e aconselhados, são procurados pelos turistas, nomeadamente as levadas que atravessam áreas agrícolas nos setores de menor altitude da face sul da ilha (Figura 10).
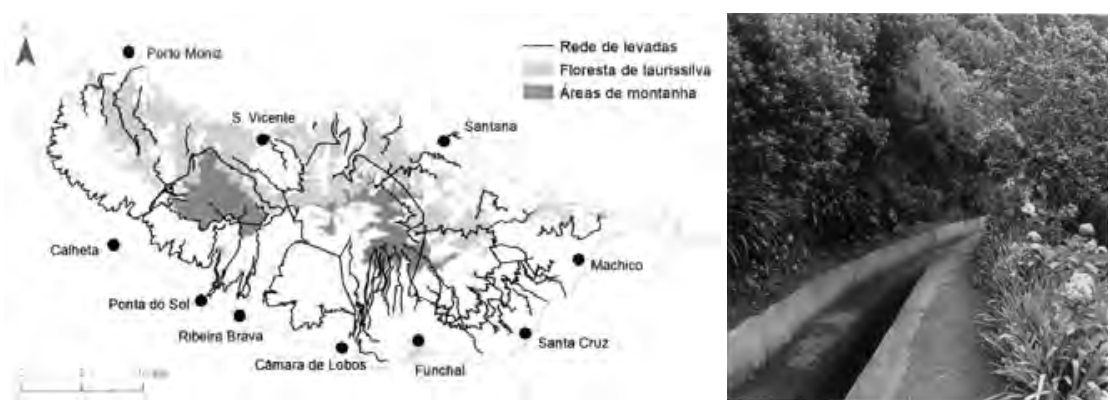

Figura 10

Rede de levadas e áreas de paisagem natural com interesse turístico na ilha da Madeira (esq.) e pormenor de uma levada (dir.) Fotografia de Albano Figueiredo, 2016 
Presentemente existem no destino turístico Madeira 30 percursos pedonais recomendados, 28 percursos na ilha da Madeira (10 em levadas, $13 \mathrm{em}$ veredas, 3 em caminhos reais e 2 noutro tipo de caminhos) e 2 percursos na ilha do Porto Santo (ambos em veredas) (JORAM, 2012). ${ }^{10}$

Para além dos percursos pedestres, é bastante frequente a realização de circuitos turísticos à volta da ilha, com passagem pelos principais centros urbanos e paragem nos miradouros distribuídos ao longo da costa (Figura 8). Esta é uma opçáo muito procurada por turistas com estadas curtas, assim como por passageiros de navios de cruzeiro. Estes percursos estão baseados essencialmente na possibilidade de contemplar a paisagem natural e aceder aos locais mais emblemáticos da ilha, onde os miradouros desempenham um papel fundamental, permitindo vistas privilegiadas sobre extensas áreas da paisagem e lugares de interesse específico.

\section{Diversidade climática}

Um dos aspetos que mais favorece a escolha deste destino é o clima, não só pela sua amenidade, como pela diversidade. A ilha apresenta condiçôes bem diferenciadas em função da altitude e da exposição aos ventos dominantes, os alísios, dando origem a uma marcada assimetria entre as faces norte e sul, e um contraste bem marcado entre os setores de maior altitude (1500-1800m) e as áreas costeiras $(<300 \mathrm{~m})$. Para tal contribui a disposição perpendicular do sistema montanhoso principal, que atravessa a ilha da Madeira no sentido este-oeste no centro da ilha (Figura 6), e que se apresenta como uma importante

\footnotetext{
${ }^{10}$ Data do ano 2000 o Decreto Legislativo Regional (Decreto n. ${ }^{07-B / 2000 / M) ~(P o r t u g a l, ~ 2000) ~}$ que estabelece os percursos pedonais recomendados na Regiâo Autónoma da Madeira, num total de 58 pequenas rotas (PR). Em 2010 um Despacho conjunto das Secretarias Regionais do Turismo e Transportes e dos Recursos Naturais, datado de 20 de Agosto de 2010, aprova uma nova lista de percursos pedonais, restringindo a 27 os percursos (24 percursos na ilha da Madeira e 3 na ilha do Porto Santo) (JORAM, 2010). O objetivo dos Despachos de 2010 e de 2012 (JORAM, 2010; JORAM, 2012) foi proceder a uma atualizaçáo da lista de percursos, que decorre de trabalhos de recuperação, de beneficiação, de redefinição de trajetos e de implementaçẫo de sinalética, medidas de ação essenciais para conferir segurança aos percursos recomendados.
} 
barreira relativamente aos ventos alísios. Responsável por valores de precipitação mais elevados na face norte e setores de maior altitude, esta barreira promove ainda a formação frequente de nevoeiros na face norte da ilha. Assim, a um ambiente mais húmido e fresco da face norte, contrapóe-se o ambiente mais quente e seco das áreas de baixa altitude $(<300 \mathrm{~m})$ da costa sul, áreas onde se concentra a maior parte dos empreendimentos turísticos. Estas áreas costeiras junto ao mar apresentam temperaturas médias anuais superiores a $17^{\circ} \mathrm{C}$, e valores de precipitação inferiores a $500 \mathrm{~mm}$. O número de dias com precipitação é normalmente inferior a 80, e a temperatura diurna nos meses de inverno frequentemente está próxima dos $20^{\circ} \mathrm{C}^{11}$. Nestas áreas o número de noites tropicais $^{12}$ por ano pode ser entre 40 e 50, podendo o número de dias de verão ${ }^{13}$ oscilar entre 60 e 70 dias. Tendo em conta estas condições climáticas claramente subtropicais, estas áreas são adequadas à prática de turismo ao ar livre mesmo no inverno. Esta pode ser uma das razóes por que as escalas de cruzeiro são especialmente importantes entre novembro e abril (Figura 5). Sendo estas condiçôes características de uma franja restrita das áreas costeiras na face sul da ilha, este pode ser um dos fatores que determina a assimetria existente ao nível da distribuição de empreendimentos turísticos entre as duas faces da ilha, duplicando a realidade que se identifica no povoamento.

Em oposição às condiçôes descritas anteriormente para as áreas costeiras da face sul, os setores de maior altitude (1500-1850 m) apresentam um elevado número de dias com precipitação, que pode variar entre 220 e 250 dias, e registam totais anuais entre os 3500 e os $3800 \mathrm{~mm}$, sendo os meses de junho a setembro os que registam os valores de precipitação mais baixos, ainda que apenas o mês de julho se possa considerar um mês seco. A temperatura média anual situa-se entre os 6 e os $9^{\circ} \mathrm{C}$, sendo raros os dias com temperatura superior a $25^{\circ} \mathrm{C}$ (Santos e Miranda, 2006).

\footnotetext{
${ }^{11}$ Instituto Português de Meteorologia, Normais Climatológicas - série 1971-2000.

12 Temperatura mínima superior ou igual a $20^{\circ} \mathrm{C}$.

13 Temperatura média diária superior a $25^{\circ} \mathrm{C}$.
} 
No período de inverno as condiçôes do estado do tempo são menos favoráveis na face norte da ilha e nos setores de maior altitude, implicando algumas limitaçóes à prática turística, principalmente em termos de percursos pedestres, uma das atividades mais procuradas pelos turistas que visitam a ilha da Madeira. Esta situação deve-se à maior frequência de nevoeiros e valores mais elevados de precipitaçâo, frequente registo de ventos fortes com direçấo predominante de nordeste, e temperaturas médias diárias mais baixas, condiçóes pouco adequadas à realização de caminhadas nas áreas de floresta Laurissilva, levadas da costa norte e áreas de montanha. Mas, devido à diversidade climática da ilha, neste período do ano, aproveitando as condiçóes de estado do tempo normalmente mais favoráveis na face sul, vários percursos estão disponíveis, nomeadamente levadas, caminhos reais ou veredas, neste caso construídas para fazer a ligação entre os núcleos costeiros, frequentemente localizados em fajās, e os aglomerados que se estendem em direçáo à serra. Ou ainda circuitos pelos miradouros localizados junto à costa, permitindo vistas privilegiadas sobre a paisagem costeira (Figura 8). Ambas as situaçóes podem desempenhar um papel importante à escala local, contribuindo para diversificar a oferta turística e permitir o contacto mais direto com o património, nomeadamente o património natural (Figueiredo, 2008).

Já o período de maio a setembro, período do ano com valores mais baixos de precipitação e temperaturas médias mais elevadas, apresenta condiçôes climáticas adequadas à prática do turismo ao ar livre em toda a ilha, tais como caminhadas nas levadas ou nos caminhos reais, que permitem aceder a manchas de Laurissilva ou aos setores mais recônditos da ilha. A esta atividade, somam-se diversas possibilidades em termos de lazer associado a ambientes aquáticos (pesca desportiva, whale-watching, mergulho, snorkeling, coastering, windsurf, canyoning, canoagem, passeios marítimo-turísticos).

Coincidente com o período do ano que mais pessoas escolhem para férias no hemisfério norte, é neste período que se concentra a maior procura deste destino turístico, sendo também o período em que se realiza um maior número de eventos (Figura 11). 


\section{Diversidade de eventos}

Além do património natural, o destino Madeira conta com um conjunto de eventos que ajudam a diversificar a oferta, alguns dos quais se assumem como importantes em termos de atração turística. Eventos como o Carnaval, a Festa da Flor ou a Passagem de ano funcionam já como motores em termos de atração turística.

Mas grande parte dos eventos tem lugar entre abril e outubro. Além dos eventos constantes na Figura 11, outros contribuem para diversificar a oferta, como sejam os arraiais da Madeira, festas populares que podem ter projeçấo à escala da ilha, como as Festas de Nossa Senhora do Monte, ou ainda festas ligadas às colheitas de produtos agrícolas (festa da banana, festa da anona, festa da castanha, festa da vindima, festa do limáo, festa da melancia, festa do pêro, festa da cereja, mostra da cana-de-açúcar, festa da cebola). Ainda que sejam eventos que têm capacidade para funcionar como atração turística relevante, contribuem para diversificar a natureza dos eventos propostos.

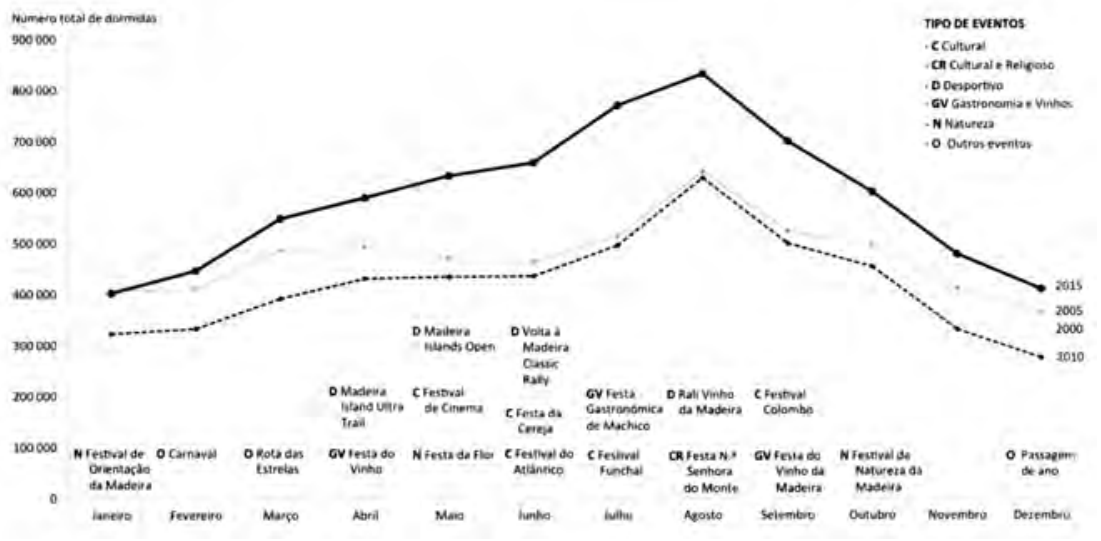

Figura 11

Número mensal de dormidas em empreendimento turístico no arquipélago da Madeira em diferentes anos $(2000,2005,2010,2014)$ e principais eventos, de acordo com o tipo de evento

Fonte dos dados: Apuramento específico, Instituto Nacional de Estatística, Lisboa, 2016. 
Ora uma das estratégias utilizadas pelas organizaçóes de gestão dos destino turísticos para aumentar a procura turística e esbater a sazonalidade que geralmente a caracteriza é a organização e promoção de eventos, de âmbito diverso (culturais, desportivos, gastronómicos, religiosos, entre outros). No caso do destino Madeira o levantamento, não exaustivo, do calendário anual dos eventos, que se faz constar na Figura 11, permite constatar que estes, além de contribuírem para diversificar a oferta, têm permitido aumentar a procura turística entre os meses de abril a outubro, tal como se pode verificar através da análise comparativa do número mensal de dormidas em empreendimento turístico nos anos 2000 e 2014. Ainda assim, um calendário de eventos adequadamente estruturado e com divulgação mais ampla poderá contribuir para reduzir o efeito da sazonalidade da procura turística no destino Madeira.

\section{Consideraçôes finais}

Este texto, in memoriam, ao Dr. António Gama, contempla um destino turístico específico: a Madeira. A Madeira vivenciou, desde a centúria de oitocentos, em que se tornou nacional e internacionalmente uma reconhecida estância terapêutica, um crescimento muito apreciável da atividade turística. $\mathrm{O}$ turismo assume na Madeira uma importância socioeconómica muito significativa, constituindo-se este como um dos mais importantes destinos turísticos de Portugal.

Nos territórios insulares, como a Madeira, os transportes aéreos e marítimos adquirem uma importância fulcral, não só em termos de conectividade inter-ilhas como para a acessibilidade externa, nacional e internacional, sendo a construção de estruturas aeroportuárias e portuárias essencial para a sua competitividade, designadamente como destinos turísticos. No caso da Madeira, a criação dos aeroportos e dos portos do Funchal e do Porto Santo, relevou-se como essencial para a afirmação do arquipélago como destino turístico. As sucessivas intervençóes nas estruturas portuárias e as parcerias com autoridades portuárias congéneres têm permitido que a Madeira se (re)posicione em termos de turismo de cruzeiros, que é estratégico para a sua afirmação como destino turístico. 
$\mathrm{Na}$ Madeira o património natural, o padrão climático anual e o calendário anual de eventos contribuem para explicar a variaçáo intra-anual da procura turística, como se demonstra. Pelas suas caraterísticas, o património natural da ilha da Madeira apresenta-se como um dos fatores que mais contribui para a atratividade deste destino turístico. Ainda que o destino seja afetado pela sazonalidade, o turismo de cruzeiros contribui para esbater a mesma, principalmente nos meses em que se regista um menor número de dormidas no destino. No destino Madeira, as condiçôes climáticas que caraterizam o estado do tempo entre o final do outono e o início da primavera condicionam a prática de atividades de lazer ao ar livre, como o pedestrianismo, traduzindo-se num menor número de dormidas. Os eventos, que se concentram fundamentalmente na primavera e no verão, têm contribuído para aumentar o número de dormidas nestas estaçóes do ano, sendo estratégico investir em eventos que ocorram no outono e inverno, e que tenham duraçóes mais alargadas para fazerem aumentar a estada média na ilha.

Presentemente, um dos pontos fracos identificados pelo Plano de Açâa para o Desenvolvimento do Turismo em Portugal Turismo 2020 para o destino Madeira é a reduzida investigação em turismo (TP, 2015: 134). Neste sentido, o destino muito beneficiará, no futuro, do aumento da investigação científica, uma investigação que informe os agentes e os grupos de interesse locais, no sentido de robustecer o sistema turístico regional, tornando-o mais inovador e competitivo.

\section{Referências bibliográficas}

Administração dos Portos da Regiāo Autónoma da Madeira (APRAM) (2016). Sítio da Administração dos Portos da Regiāo Autónoma da Madeira. Disponível em http://www.portosdamadeira.com/ site/index.php/pt/ Acedido a 15 de julho de 2016.

Almeida, A. M. M. (2010). From island mass tourism to rural tourism In Madeira: Is there a place for a re-definition of islands' image? Polytechnical Studies Review, VIII, 14, pp. 97-110.

Associação Comercial e Industrial do Funchal, Câmara de Comércio e Indústria da Madeira (ACIF-CCIM) (2015). Documento estratégico para o turismo na RAM. Relatório diagnóstico ao atual posicionamento da Madeira. Funchal: Associação Comercial e Industrial do Funchal, Câmara de Comércio e Indústria da Madeira. 
Brito-Henriques, E. (2008). Representaçóes da insularidade e turismo: que possibilidades para as ilhas portuguesas? In Carminda Cavaco (coord.), Turismo, Inovação e Desenvlvimento (pp. 123-142). Lisboa: Centro de Estudos Geográficos, Universidade de Lisboa.

Direção Regional de Estatística da Madeira (DREM) (2015). Estatísticas do turismo da Região Autónoma da Madeira. Funchal: Direçấo Regional de Estatística da Madeira.

Figueiredo, A. (2008). Calheta: Património natural. Coimbra: Imprensa da Universidade de Coimbra.

Gama, A. (1977). Algumas notas sobre as relaçóes entre a Geografia e as Ciências Sociais. Biblos, LIV, pp. 137-143.

Gama, A. (1988). Notas para uma Geografia do tempo livre. Cadernos de Geografia, 7, 203-217. Disponível em http://www.uc.pt/fluc/depgeotur/publicacoes/Cadernos_Geografia/Numeros_ publicados/CadGeo7/artigo12_Acedido a 8 de janeiro de 2016.

Gomes, C. de S. F., Silva, J. B. P. (2012). Ilha do Porto Santo: estância singular de saúde naturall Porto Santo Island: unique natural health resort. Funchal: Madeira Rochas, Divulgaçôes Científicas e Culturais.

Instituto Canario de Estadística (ISTAC) (2016). RevPAR 2014. Gran Canária: Instituto Canário de Estadística. Disponível em http://www.gobiernodecanarias.org/istac/jaxi-istac/tabla.do Acedido a 29 de julho de 2016.

Instituto Nacional de Estatística (INE) (2016). Anuário Estatístico da Regiāo Autónoma da Madeira 2015. Lisboa: Instituto Nacional de Estatística.

Jornal Oficial da Regiāo Autónoma da Madeira (JORAM) (2010). II Série, número 157, de 20 de agosto de 2010, Despacho conjunto das Secretarias Regionais do Turismo e Transportes e dos Recursos Naturais que aprova as alteraçóes à lista dos percursos pedonais recomendados na Regiäo Autónoma da Madeira. Disponível em http://www.sra.pt/drf/files/Percursos\%20Pedestres\%20-\%20 Panfletos/legislacao/IISerie-157-2010-08-20.pdf Acedido a 15 de julho de 2016

Jornal Oficial da Regiāo Autónoma da Madeira (JORAM) (2012). II Série, número 74, de 30 de abril de 2012, Despacho conjunto das Secretarias Regionais do Ambiente e Recursos Naturais e da Cultura, Turismo e Transportes que aprova a lista de percursos pedonais recomendados na Região Autónoma da Madeira. Disponível em http://www.sra.pt/drf/files/Percursos\%20Pedestres\%20 -\%20Panfletos/legislacao/Despacho\%202012\%20Lista\%20dos\%20percursos\%20pedonais\%20 recomendados.pdf_Acedido a 15 de julho de 2016.

Mangorrinha, J. (coord.) (2012). História de uma viagem: 100 anos de turismo em Portugal (1911-2011). Ponta Delgada: Turismo de Portugal, Comissão Nacional do Centenário do Turismo de Portugal.

Marujo, N. (2012). Turismo, turistas e eventos: o caso da ilha da Madeira. Dissertaçáo de doutoramento em turismo. Évora: Universidade de Évora.

Marujo, N. (2015). O desenvolvimento do turismo na ilha da Madeira. TURyDES, Revista de Turismo y Desarrollo, 6(15), pp. 1-16.

Moreira, C. O. (2013). Turismo, território e desenvolvimento: competitividade e gestão estratégica de destinos. Tese de doutoramento em Turismo, Lazer e Cultura. Coimbra: Universidade de Coimbra.

Oliveira, P., Pereira, P. T. (2008). Who values what in a tourism destination? The case of Madeira Island. Tourism Economics, 14, 1, 155-168.

Portugal (2000). Diário da República, I série-A, n. ${ }^{\circ}$ 67, 20 de Março de 2000, Regiāo Autónoma da Madeira, Decreto Legislativo Regional n. ${ }^{\circ}$ 7-B/2000/M. Estabelece os percursos pedonais 
recomendados na Regiāo Autónoma da Madeira. Disponível em http://www.sra.pt/drf/files/ Percursos\%20Pedestres\%20-\%20Panfletos/legislacao/00020007.pdf.

Ribeiro, O. (1985). A ilha da Madeira até meados do século XX: estudo geográfico. Lisboa: Instituto de Cultura e Língua Portuguesa.

Quintal, R. (2010). Madeira levadas: the water ways to discover nature. In Eduardo Brito-Henriques, João Sarmento, Maria Alexandre Lousada, Water and tourism: resources management, planning and sustainability (pp. 169-191). Lisboa: Centro de Estudos Geográficos, Universidade de Lisboa.

Santos, F. D., Miranda, P. (eds.) (2006). Alteraçōes climáticas em Portugal. Cenários, impactos e medidas de adaptaçấo. 1. ${ }^{a}$ ed. Lisboa: Gradiva.

Secretaria Regional do Turismo e Transportes (SRTTM) (2010). Estudo do gasto turístico. ECAM, Funchal. Disponível em http://www.acif-ccim.pt/Admin/Public/Download.aspx?file=Files/ Filer/ACIF/Paginas/estudo_gasto_turistico.pdf Acedido a 3 de maio de 2016.

Sousa, J. F. (2004). O porto do Funchal no contexto do sistema portuário insular regional. As infraestruturas, os tráfegos e as funçöes portuárias. Tese de doutoramento. Lisboa: Universidade Nova de Lisboa.

Turismo de Portugal (TP) (2015). Turismo 2020 Plano de Ação para o Desenvolvimento do Turismo em Portugal. Lisboa: Turismo de Portugal.

Turismo de Portugal (TP) (2016). Registo Nacional dos Agentes de Animação Turística. Lisboa: Turismo de Portugal. Disponível em https://rnt.turismodeportugal.pt/RNAAT/ConsultaRegisto. aspx? Origem=CP\&FiltroVisivel=True Acedido a 31 de agosto de 2016. 